\title{
Species assemblages and diversity of litter ants (Hymenoptera: Formicidae) along an altitudinal gradient across two vegetation types in Hanthana Forest in Kandy, Sri Lanka
}

\section{W.A.I.P. Karunaratne and D.A.G.N.B. Karunarathna}

Litter ants of two vegetation types of the Hanthana Forest

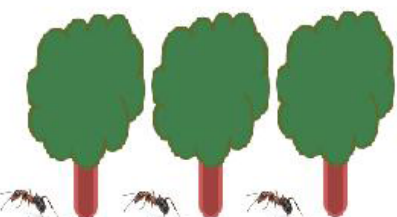

Mixed woodland

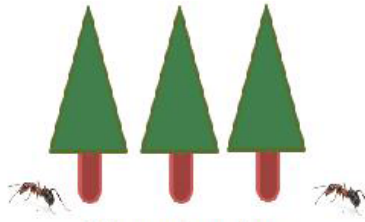

Pinus plantation

Litter ant collection using hand picking and Winkler extraction methods yielded 9 subfamilies, 32 genera and 56 morpho-species

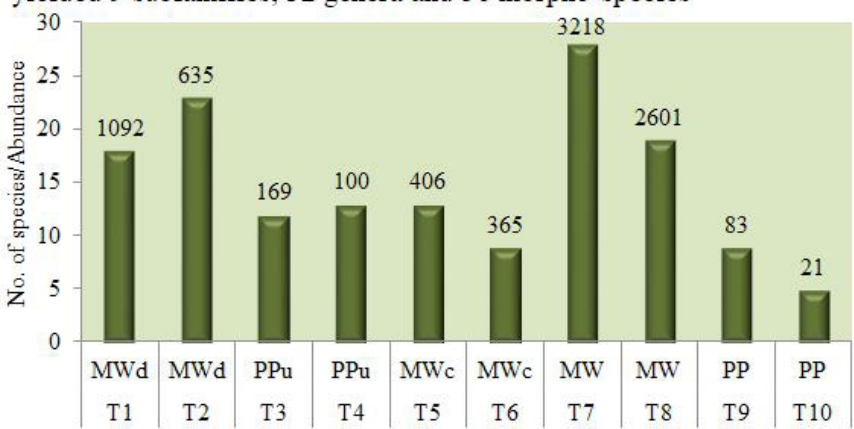

400 to $500 \mathrm{~m}$ - Mixed woodland (disturbed) (MWd)

500 to $600 \mathrm{~m}$ - Pine plantation (sparse ground cover of broad-leaf weeds) (PPu)

600 to $700 \mathrm{~m}$ - Mixed woodland (abandoned coffee plantation) (MWc)

700 to $800 \mathrm{~m}-$ Mixed woodland (somewhat undisturbed) (MW)

800 to $900 \mathrm{~m}$ - Pure Pine plantation (without ground cover) (PP)

\section{Highlights}

- The study yielded 9 subfamilies 32 genera and 56 morpho-species of ants from the two vegetation types.

- Genus Pheidole had the highest number of species while Solenopsis sp. 1 was the most widely distributed and abundant species.

- The mixed woodlands, regardless of elevation, were richer in ant species than pine plantations.

- The difference in litter ants in Hanthana Forest is possibly due to differences in vegetation types rather than altitude. 
SHORT COMMUNICATION

\title{
Species assemblages and diversity of litter ants (Hymenoptera: Formicidae) along an altitudinal gradient across two vegetation types in Hanthana Forest in Kandy, Sri Lanka
}

\author{
W.A.I.P. Karunaratne* and D.A.G.N.B. Karunarathna \\ Department of Zoology, Faculty of Science, University of Peradeniya, Peradeniya, Sri Lanka
}

Received: 10/10/2019 ; Accepted: 16/05/2020

\begin{abstract}
Ants account for $30 \%$ of terrestrial biomass and are highly sensitive to environmental variables. Present study investigated the effect of altitude $(400-900 \mathrm{~m})$ and vegetation type (mixed woodland and pine plantations in Hanthana forest) on litter ants. Two transects were laid at each of the five $100 \mathrm{~m}$ elevation levels. For hand-picking and litter extraction of ants, $1 \mathrm{~m}_{2}$ plots were laid at every $20 \mathrm{~m}$ intervals along the two sides of each transect. A total of 8689 ants in 9 subfamilies 32 genera and 56 morpho-species were collected. Subfamily Myrmicinae had the highest number of genera (15) and species (26 spp.). Genus Pheidole was represented by the highest number of species (5 spp.) while Solenopsis sp. 1 was the most widely distributed and abundant (6420 individuals) species. The mixed woodlands, regardless of elevation, were richer in ant species than pine plantations. Permutation test $(\rho=0.30, P=3 \%)$ revealed a weak relationship between ant assemblages and environmental variables. Findings indicated that the difference in litter ant species assemblages and diversity in Hanthana Forest is possibly due to differences in vegetation types rather than altitude.
\end{abstract}

Keywords: Litter ants; species assemblages; altitudinal gradient; Hanthana forest.

\section{INTRODUCTION}

Ants which account for an estimated 30\% of terrestrial biomass are the most dominant group of social insects in major habitats around the world saturating a wide range of feeding niches in soil and vegetation. Along with termites, ants are the most important group of insects in tropical rain forests in terms of biomass, number of individuals and ecological impact (Holldobler and Wilson, 1990).

Soil-inhabiting ants play a considerable role in mineralization processes because of their extensive digging activity. Hence, they are highly sensitive and respond rapidly to environmental changes (Van der Woude et al., 1997). Silva et al., (2017) found that litter ants do not reflect the holistic picture of arthropod diversity and assemblages in leaf litter, but the quality of the habitat for the survival of all litter arthropods. Gunawardene et al., (2012) found that ant assemblages respond to plant structure at ground level rather than to tree species diversity in a lowland dipterocarp-dominated forest in Sri Lanka. According to Thuenis et al., (2005) ant species distributions were related to the quality and weight of leaf litter. However, limited studies have been conducted to investigate the diversity and species assemblages of ants along an altitudinal gradient (Samson et al., 1997; Bruhal et al., 1999; Bharti, 2008) that encompasses different climatic conditions and vegetation structure. In Sri Lanka, though ant species composition in many habitat types has been established, the effect of altitudinal gradient on ant species assemblages has not been explored. Therefore, the present study was conducted to investigate the effect of altitude and forest type on species assemblages and diversity of litter ants in Hanthane Forest in Kandy, Sri Lanka.

\section{MATERIALS AND METHODS}

\section{Study Site}

Hanthana Mountain Range which ranges in elevation from $500 \mathrm{~m}-1200 \mathrm{~m}$ encompassing different vegetation types lies in the Kandy District in central Sri Lanka (Latitude/ longitude: $\left.07^{\circ} 16^{\prime} 11^{\prime \prime} \mathrm{N} 80^{\circ} 37^{\prime} 47^{\prime \prime} \mathrm{E}\right)$. The study sites were demarcated along an elevation gradient to include two vegetation types; mixed woodland and pine plantations along an elevation gradient ranging from $400 \mathrm{~m}$ to $900 \mathrm{~m}$. Study sites were selected within each $100 \mathrm{~m}$ elevation level to incorporate five different sub-elevation levels as given below.

400 to $500 \mathrm{~m}$ - Mixed woodland (disturbed) (MWd)

500 to $600 \mathrm{~m}$ - Pine plantation (with sparse ground cover of broad-leaf weeds) (PPu)

600 to $700 \mathrm{~m}$ - Mixed woodland (an abandoned coffee plantation) (MWc)

700 to $800 \mathrm{~m}$ - Mixed woodland (somewhat undisturbed) (MW)

800 to $900 \mathrm{~m}$ - Pure Pine plantation (without ground cover of weeds) (PP)

\section{Sampling of litter ants}

A $100 \mathrm{~m}$ line transect was laid down within each vegetation type perpendicular to the slope. Ants were collected using two methods, i.e., Winkler extraction (Bestelmeyer et al., 2000) and hand picking. One square meter quadrates were laid at every $20 \mathrm{~m}$ interval on both sides along each transect. Litter in $1 \mathrm{~m} 2$ quadrates laid at every $20 \mathrm{~m}$ interval 
along one side of each transect was collected for Winkler extraction. Collected litter samples were sieved to remove larger litter particles and the rest was collected into a cloth bag to carry into the laboratory for ant extraction. Along the other side of each transect at every $20 \mathrm{~m}$ interval, $1 \mathrm{~m} 2$ quadrate was thoroughly examined for the presence of litter ants. Small quantities of litter at a time was collected and placed on a white tray to examine and collect ants using forceps. Ants from each quadrate were preserved in 70\% alcohol and stored in labeled vials.

This procedure was conducted twice at each of the five $100 \mathrm{~m}$ elevation level for a period of one year from 20112012. A total of 10 transects were laid at 10 places of the five elevation levels to sample ants in the Hanthana Forest during the present study.

\section{Identification of ants}

Three to four representative specimens of each morphospecies were card mounted to make a reference collection and the rest were stored in $90 \%$ ethanol. Ants were identified up to the subfamily, genus and morpho-species using taxonomic keys, descriptions (Bolton, 1994; Bingham, 1903), and the reference collection lodged in the Department of Zoology, University of Peradeniya.

\section{Determining whether parameters and ground cover characteristics}

At each site, air temperature (oC), relative humidity (RH) and light intensity at five points along each transect were measured using Kestrel 3500 pocket weather meter. Ground cover characteristics were quantified by estimating the percentage coverage by bare ground, leaf litter, large rocks, and plant stems in a $1 \mathrm{~m} 2$ quadrate. Estimations were made in five quadrates along each transect and averaged.

\section{Statistical Analysis}

Data on number of ant species and individuals with respect to vegetation type, altitude, weather parameters and ground cover characteristics were analyzed using Primer v6 software. Diversity of ants in different vegetation types and elevation levels were calculated using species richness (Margalef diversity index, Simpson dominance), and evenness indices (Simpson evenness index). Cluster analysis was performed to check the similarity of ant assemblages among the different study sites. A relate test was performed for ant species matrix and environmental and litter parameter matrix using Euclidean distance. A permutation test (Relate test) was applied to the matching coefficient $\rho$ (Rho) between the ant abundance matrix and site characteristics matrix which were independently derived and have sample labels which can me matched up.

Two-sample $t$-test was carried to test any difference between the ants collected from hand picking method and Winkler extraction method using Minitab 14.

\section{RESULTS AND DISCUSSION}

A total of 8689 specimens of ants belonging to 9 subfamilies, 32 genera and 56 morpho-species were found along an elevation gradient ranging from $400 \mathrm{~m}$ to $900 \mathrm{~m}$ in the Hanthana Forest (Table 1). This accounts for $\sim 26 \%$ out of 215 species in 64 genera (Dias and Rajapaksa, 2016) recorded in Sri Lanka. Five subfamilies contained only a single genus and a species. Subfamily Myrmicinae included the highest number of ant genera (15) and species followed by Ponerinae (7 and 15 respectively) (Table 1). According to Dias et al. (2012), Myrmecinae, Ponerinae and Formicinae are the most common three subfamilies account for $75 \%$ of generic diversity and $80 \%$ of the species diversity in Sri Lanka.

Seventeen genera of ants contained only a single species while nine genera contained two species (Figure 1). The most species rich genus, Pheidole was represented by five species and Solenopsis sp. 1 was the most widely distributed and abundant species of which 6420 individuals were recorded. This was abundant in mixed woodland habitats but completely absent in the pure pine plantation. According to Uys (2012), dominant species can vary in different forest types because these species dependent on habitat conditions, micro climate, food sources and competition.

The monotypic genus Dorylus (Dorylinae), a subterranean army ant of the subfamily Dorylinae was also recorded in the present study. This was represented by a single specimen and is known to be a very rare subfamily not discovered even in an extensive study conducted in Sinharaja Forest Reserve by Gunawardene et al, (2008). However, the present study failed to spot the Sri Lankan relict ant, Aneuretus simony, a twig nesting species recorded by Wilson et al. (1956) from Peradeniya and Kandy. Karunarathna and Karunaratne (2013) recorded this species from a wet zone forest, Moraella and an intermediate zone forest in Knuckles Forest Reserve.

Figure 1 gives the accumulation of ant species by the two collecting methods. Accordingly, Winkler extraction method yielded a larger number of species compared to hand picking method. Number of ant species significantly differed ( $p=0.002)$ between the two collecting methods while genera was not significant $(p=0.079)$. According to Bestelmeyer et al., (2000), hand collection is often difficult to standardize as samples collected are influenced by the skill and efficiency of the collectors. Furthermore, these species accumulation curves did not reach a plateau (Figure 1 indicating that the study sites were under sampled. Majority of the genera recorded during the present study contained a single or two species. Therefore, there is a possibility of recording more species if sampling was continued throughout the year. However, even in larger studies, it is impossible and impractical to completely capture all the species in a hyper-diverse taxon like ants, especially in tropical forests (Longino and Colwell, 1997).

According to Table 2, the forest types with the highest number of species were mixed woodland (MW) at 700 - $800 \mathrm{~m}$ elevation and the disturbed mixed woodland (MWd) at $400-500 \mathrm{~m}$ elevation. Compared to these two sites, the number of ant species was low in the mixed woodland, which is an abandoned coffee plantation (MWc) at $600-700 \mathrm{~m}$ elevation. Only a few species of ants were encountered from the pure pine (PP) plantation compared to the pine plantation with sparse ground cover 
Table 1: Subfamily, Genera and the number of morpho-species of ants collected from the Hanthana Forest Reserve.

\begin{tabular}{|c|c|c|}
\hline Subfamily (No. G/M-spp.) & Genus & No. of Morpho-species \\
\hline Amblyopononae (1/1) & Amblyopone & 01 \\
\hline Cerapahynae (1/1) & Cerapachys & 01 \\
\hline Dorylinae $(1 / 1)$ & Dorylus & 01 \\
\hline \multirow[t]{2}{*}{ Dolichoderinae $(2 / 5)$} & Tapinoma & 02 \\
\hline & Technomermex & 03 \\
\hline \multirow[t]{3}{*}{ Formicinae $(3 / 4)$} & Acropyga & 01 \\
\hline & Anoplolepis & 02 \\
\hline & Paratrechina & 01 \\
\hline Leptanillinae (1/1) & Leptanilla & 01 \\
\hline \multirow[t]{15}{*}{ Myrmicinae $(15 / 26)$} & Cataulacus & 01 \\
\hline & Indomyrma & 01 \\
\hline & Meranoplus & 03 \\
\hline & Myrmecina & 01 \\
\hline & Kartidris & 01 \\
\hline & Oligomyrmex & 02 \\
\hline & Pheidole & 05 \\
\hline & Pheidologeton & 01 \\
\hline & Ponera & 02 \\
\hline & Quadristuma & 02 \\
\hline & Recurvidris & 01 \\
\hline & Solenopsis & 02 \\
\hline & Strumigenys & 01 \\
\hline & Tetramorium & 02 \\
\hline & Wasmania & 01 \\
\hline \multirow[t]{7}{*}{ Ponerinae $(7 / 15)$} & Anochetus & 02 \\
\hline & Cardiocondyla & 01 \\
\hline & Diacamma & 01 \\
\hline & Hypoponera & 01 \\
\hline & Leptogenys & 04 \\
\hline & Odontomachus & 03 \\
\hline & Pachycondyla & 03 \\
\hline Pseudomyrmicinae (1/1) & Tetraponera & 02 \\
\hline Total: 09 & 32 & 56 \\
\hline
\end{tabular}

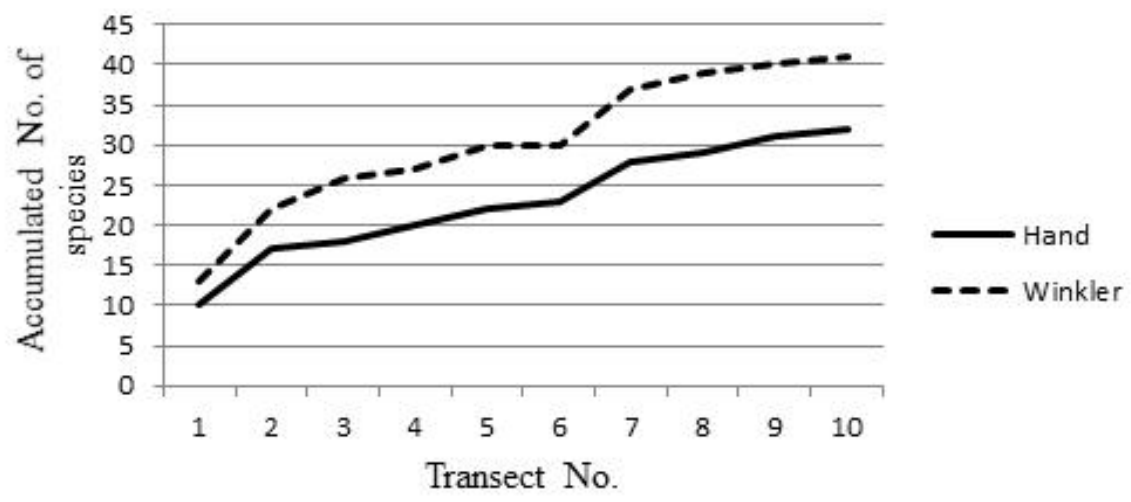

Figure 1: Species accumulation curves for the ants collected from the hand picking method and Winkler extraction method along the 10 transects installed along an elevation gradient in the Hanthana Forest Reserve. 
Table 2: Species richness, abundance and diversity indices of ants sampled along the 10 transects in the Hanthana Forest Reserve.

\begin{tabular}{|c|c|c|c|c|c|c|c|}
\hline 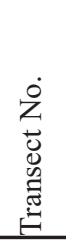 & 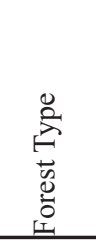 & 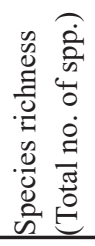 & 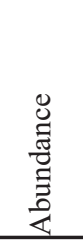 & 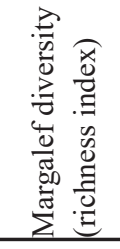 & 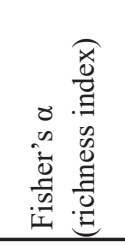 & 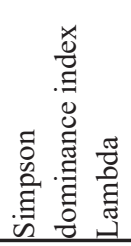 & 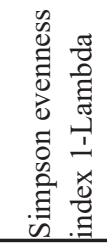 \\
\hline $\mathrm{T} 1$ & MWd & 18 & 1092 & 2.43004 & 3.06138 & 0.52028 & 0.47972 \\
\hline $\mathrm{T} 2$ & MWd & 23 & 635 & 3.40894 & 4.67626 & 0.54363 & 0.45637 \\
\hline $\mathrm{T} 3$ & $\mathrm{PPu}$ & 12 & 169 & 2.14429 & 2.95230 & 0.25017 & 0.74983 \\
\hline $\mathrm{T} 4$ & $\mathrm{PPu}$ & 13 & 100 & 2.60577 & 3.98591 & 0.12540 & 0.87460 \\
\hline T5 & MWc & 13 & 406 & 1.99788 & 2.56345 & 0.50835 & 0.49165 \\
\hline T6 & MWc & 9 & 365 & 1.35596 & 1.66908 & 0.77278 & 0.22722 \\
\hline $\mathrm{T} 7$ & MW & 28 & 3218 & 3.34303 & 4.21782 & 0.69907 & 0.30093 \\
\hline $\mathrm{T} 8$ & MW & 19 & 2601 & 2.28901 & 2.77632 & 0.57357 & 0.42643 \\
\hline T9 & PP & 9 & 83 & 1.81043 & 2.56647 & 0.16272 & 0.83728 \\
\hline T10 & PP & 5 & 21 & 1.31383 & 2.07618 & 0.26077 & 0.73923 \\
\hline
\end{tabular}

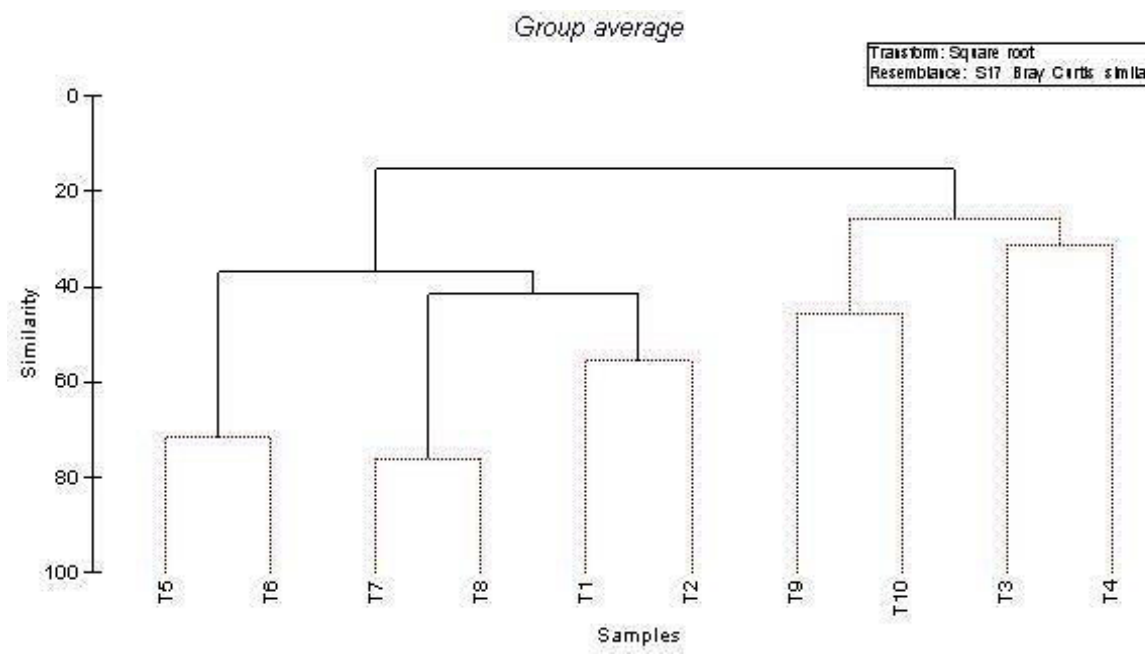

Figure 2: Dendrogram of ten $100 \mathrm{~m}$ transects (T1 \& T2 - MWd; T3 \& T4 - Ppu; T5 \& T6 - MWc; T7 \& T8 - MW; T9 \& T10 - sampled for ants along an altitudinal gradient in the Hanthana Forest Reserve using group average clustering from Bray-Curtis similarities (samples connected by solid lines are significantly different while that of dotted lines are not).

of broad-leaf weeds $(\mathrm{PPu})$ that harboured a comparatively higher number of species. The highest species number and abundance of litter ants in mixed woodland may be largely due to its diverse habitat heterogeneity compared to pure pinus plantations that consist of adult pine trees with a thick mat of decaying pine needles and debris with almost no understory vegetation (Murray et al., 2009).

The overall comparison shows that Pine plantations were not rich in ant species compared to the mixed woodlands in the Hanthana Forest. Similarly, the abundance of ants was found in the order of $\mathrm{MW}>\mathrm{MWd}>\mathrm{MWc}>\mathrm{PPu}$ and PP. The highest values for both Margalef diversity and Fisher's $\alpha$ were recorded by MW and MWd. Simpson dominance index was lowest in Pine plantations (in Both PP and PPu) while Simpson evenness index was highest in both Pine plantations.

Cluster analysis revealed distinct differences among the ant assemblages found in the five study sites (Figure 2). Accordingly, the two major vegetation types (pine and mixed woodlands) separated at $20 \%$ similarity threshold indicating a significant difference in ant assemblages between the study sites with two different vegetation types. The two different pine plantations, one with a sparse undergrowth of broadleaf weeds (where the transect T3 and T4 were laid) and the pure pine plantations (where the transect T9 and T10 were laid) were different in relation to ant assemblages. However, the ant assemblages recorded from the two pine plantations (T9 and T10) was not different. Similarly, there is a significant difference in ant assemblages between the groups T1, T2, T7, T8 and the group T5, T6. All these transects were from different mixed woodlands, but T5 and T6 indicated a completely different ant assemblage in woodland which was an abandoned coffee plantation more than 100 years before. 
According to the analysis, the $\rho$ value $0.3(\mathrm{P}=3 \%)$ which falls within the simulated values indicated a weak relationship between the ant assemblages and site characteristics given as weather parameters and ground cover characteristics.

The overall findings of this study indicated that the vegetation type may be the major factor that governs the difference in ant assemblages irrespective of the altitude of each study site. The small altitudinal range from $400 \mathrm{~m}$ to $1200 \mathrm{~m}$ within which the Hanthana Forest falls in may be the reason for not having a relationship of ant assemblages. This result is similar to the study conducted by Ribas and Schoereder (2007) who found that tree density and structural heterogeneity affected species richness of litter ants in the Brazilian Pantanal. Therefore, the present study highlights the importance of natural forests in supporting litter ant fauna that play a major role as ecosystem engineers.

\section{DECLARATION OF CONFLICT OF INTEREST}

The authors declare no conflict of interest.

\section{ACKNOWLEDGEMENTS}

Financial support given by the Peradeniya University Research Grant: RG/2011/38/S and field help given by graduate students are greatly acknowledged.

\section{REFERENCES}

Bestelmeyer, B.T., Agosti, D., Alonso, L.E., Brandao, C.R.F., Brown Jr., W.L., Delabie, J.H.C. and Silvester, R. (2000). Field techniques for the study of grounddwelling ants. In: Agosti D., Majer, J.D., Alonso, L.E., and Schultz, T.R. (Eds.): Ants: Standard methods for measuring and monitoring biodiversity - Smithsonian Institute Press, Washington, DC, 122-144.

Bharti, H. (2008) Altitudinal Diversity of Ants in Himalayan Regions (Hymenoptera: Formicidae). Sociobiology 52(2): 305-322.

Bingham, L.C.T. (1903) The fauna of British India including Ceylon and Burma. Hymenoptera vol. II. Ants and Cuckoo-wasps. Taylor and Francis. London. $506 \mathrm{pp}$.

Bolton, B. 1994. Identification guide to the ant genera of the world: Harvard University Press, Cambridge, Mass. $222 \mathrm{pp}$

Bruhl, C.A., Mohamed, M. and Linsenmair, K.E. (1999) Altitudinal Distribution of Leaf Litter Ants along a Transect in Primary Forests on Mount Kinabalu, Sabah, Malaysia. Journal of Tropical Ecology, 15(3): 265-277. https://doi.org/10.1017/S0266467499000802

Dias, R.K.S., Kosgamage, K.R.K.A. and Peiris, H.A.W.S. (2012). The taxonomy and conservation status of ants (Order: Hymenoptera, Family: Formicidae) in Sri Lanka. The National Red List 2012 of Sri Lanka, 11.

Gunawardene, N., Majer, J. and Edirisinghe, J. (2012). Correlates of ant (Hymenoptera: Formicidae) and tree species diversity in Sri Lanka. Myrmecological News 17: 81-90.

Gunawardene, N.R., Majer J.D. and Edirisinghe J.P. (2008). Diversity and richness of ant species in a lowland wet forest reserve in Sri Lanka. Asian Myrmecology 2: 7183.

Holldobler, B. and Wilson, E.O. (1990). The ants. Belkual) Press of Harvard Uniiversity Press, Camilbridge. 732.

Karunarathna, D.A.G.N.B. and Karunaratne, W.A.I.P. (2013). Two new localities of Sri Lankan Relict Ant Aneuretus simoni Emery, 1893 (Formicidae: Aneuretinae) with the very first record in the intermediate zone. Journal of Threatened Taxa 5(11): 4604-4607. http://dx.doi.org/10.11609/JoTT.o3334.

Longino, J.T. and Colwell, R.K. (1997). Biodiversity assessment using structured inventory: capturing the ant fauna of a tropical rain forest. Ecological applications, 7(4): 1263-1277.

Murray, B.R., Baker, A.C. and Robson, T.C., (2009). Impacts of the replacement of native woodland with exotic pine plantations on leaf-litter invertebrate assemblages: a test of a novel framework. International Journal of Ecology. Article ID 490395, 6 pages. https:// doi.org/10.1155/2009/490395.

Ribas, C.R. and Schoereder, J.H. (2007). Ant communities, environmental characteristics and their implications for conservation in the Brazilian Pantanal. Biodiversity and Conservation 16: 1511-1520. https://doi.org/10.1007/ s10531-006-9041-x.

Samson, D.A., Rickart E.A. and Gonzales, P.C. (1997) Ant Diversity and Abundance along an elevational gradient in the Philippines, Biotropica 29(3): 349-363.

Silva, T.H.S.E., Karunarathna, N.B. and Karunaratne, W.A.I.P. (2017) Competence of Litter Ants for Rapid Biodiversity Assessments. International Journal of Biodiversity. Volume 2017, Article ID 6582191, 10 pages. https://doi.org/10.1155/2017/6582191.

Theunis, L., Gilbert, M., Roisin, Y. and Leponce, M. (2005). Spatial structure of litter-dwelling ant distribution in a subtropical dry forest. Insectes sociaux 52(4), 366-377. https://doi.org/10.1007/s00040-005-0822-0

Uys, C.J. (2012). The impact of pine plantations and alien invertebrates on native forest and fynbos invertebrate communities in Table Mountain National Park (Doctoral dissertation, University of Cape Town).

Van der Woude, C., Anderson, A.N. and Houswe, A.P.N. (1997) Ant communities as bioindicators in relation to fire management of spotted gum (Eucalyptus maculate Hook.) forest in south-east Queensland - Memories of the Museum of Victoria 56: 671-675.

Wilson, E.O., Eisner, T., Wheeler, G.C. and Wheeler, J. (1956). Aneuretus simoni Emery, a major link in ant evolution. Bulletin of the Museum of Comparative Zoology 115(03): 81-105. 